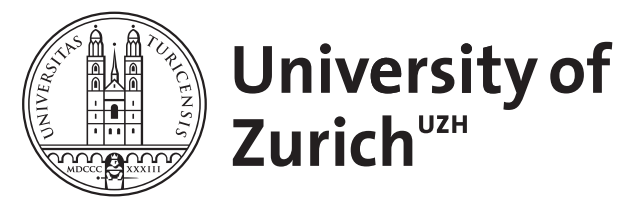

\title{
An experimental study on real option strategies
}

\author{
Wang, Mei ; Bernstein, Abraham ; Chesney, Marc
}

\begin{abstract}
We conduct a laboratory experiment to study whether people intuitively use real-option strategies in a dynamic investment setting. The participants were asked to play as an oil manager and make production decisions in response to a simulated mean-reverting oil price. Using cluster analysis, participants can be classified into four groups, which we label 'mean-reverting', 'Brownian motion real-option', 'Brownian motion myopic real-option', and 'ambiguous'. We find two behavioral biases in the strategies of our participants: ignoring the mean-reverting process, and myopic behavior. Both lead to too frequent switches when compared with the theoretical benchmark. We also find that the last group behaved as if they have learned to incorporate the true underlying process into their decisions, and improved their decisions during the later stage.
\end{abstract}

DOI: https://doi.org/10.1080/14697688.2012.691984

Posted at the Zurich Open Repository and Archive, University of Zurich ZORA URL: https://doi.org/10.5167/uzh-49680

Journal Article

Accepted Version

Originally published at:

Wang, Mei; Bernstein, Abraham; Chesney, Marc (2012). An experimental study on real option strategies. Quantitative Finance, 12(11):1753-1772.

DOI: https://doi.org/10.1080/14697688.2012.691984 


\title{
An Experimental Study On Real Options Strategies *
}

\author{
Mei Wang $^{\dagger}$ \\ Abraham Bernstein ${ }^{\ddagger}$ \\ Marc Chesney ${ }^{\S}$
}

October 31, 2012

*published in Quantitative Finance 12(11), 1753 - 1772, 2012.

$\dagger$ Corresponding author. WHU-Otto Beisheim School of Management, Burgplatz 2, 56179 Vallendar, Germany. Email:mei.wang@whu.edu.

$\ddagger$ Department of Informatics, University of Zurich, Switzerland. Email:bernstein@ ifi.uzh.ch.

§Institute of Banking and Finance (IBF) and Swiss Finance Institute, University of Zurich, Plattenstrasse 32, 8032 Zurich, Switzerland. Email:marc.chesney@bf.uzh.ch. 


\title{
An Experimental Study On Real Options Strategies
}

\begin{abstract}
We conduct a laboratory experiment to study whether people intuitively use real-option strategies in a dynamic investment setting. The participants were asked to play as an oil manager and make production decisions in response to a simulated mean-reverting oil price. Using cluster analysis, participants can be classified into four groups, which we label as "mean-reverting," "Brownian motion real-option," "Brownian motion myopic real-option," and "ambiguous." We find two behavioral biases in the strategies by our participants: ignoring the mean-reverting process, and myopic behavior. Both lead to too frequent switches when compared with the theoretical benchmark. We also find that the last group behaved as if they have learned to incorporate the true underlying process into their decisions, and improved their decisions during the later stage.
\end{abstract}

Keywords: Real Options, Experimental Economics, Heterogeneity. JEL classification: C91, D84, G31 


\section{Introduction}

In many capital budgeting scenarios, the managers have the possibility to make strategic changes, such as postponement and abandonment, during the lifetime of a project. A typical example is that an oil company may decide to temporarily shut down the production when the oil price falls below the extraction cost, whereas the same company may decide to start operation as soon as the oil price rises above the extraction cost. This has happened during the Gulf war when several oil fields in Texas and Southern California began operations when the oil price went up sufficiently to cover the relatively high extraction cost (Harvey 1999).

The strategic options like above are known as real options because the real investment can be seen as coupled with a put or call option. Real options research is one of the most fruitful fields in finance. Compared with the traditional "all-or-nothing" Net Present Value (NPV) approach, the real options method takes the advantage of "wait-and-see" and react strategically when uncertainty resolves over time. The investors can cut off unfavorable outcomes by considering the possibilities like abandonment, deferment, switching. As a result, the real options approach can substantially increase the value of a project, when compared with the less flexible NPV approach. The standard Discounted Cash Flow (DCF) criteria often undervalue investment opportunities (Dean 1951, Hayes \& Abernathy 1980, Hayes \& Garvin 1982), which would lead to myopic decisions, underinvestment and eventual losses of competitive positions because important strategic considerations are either ignored or not properly valued.

Complicated methods have been developed to evaluate a variety of real options. But in real life, people can still make different kinds of mistakes by applying the model wrongly, or misunderstanding the real options nature of a particular project.Therefore it is crucial to know whether the real options approach makes intuitive sense to investors, and if not, what are the possible pitfalls. For example, in the U.S. and other countries, the government regularly auctions off leases for offshore petroleum tracts of the land. The oil companies have to bid hundreds of millions of dollars on such tracts, thus it is important to perform valuations as accurate as possible. Given the magnitude of the stakes in such investment, even a tiny valuation mistake may cause large financial losses. But as observed by Dixit \& Pindyck (1994), even the government can arrive too low valuations, if they apply the NPV instead of real options method.

Despite extensive theoretical work on real-option modeling, empirical testing of real options has been still scarce. In particular, we know very little about how people in the real world (e.g., managers) actually value real 
options more than at an anecdotal level. It is mainly due to the intrinsic difficulties to obtain reliable data on components of the real options approach, such as the current and future value of an underlying asset, and the investors expectations of the future cash flows, etc. Previous empirical studies of real options often use either estimations or proxies for these input parameters (e.g., Quigg, 1993). Such problems may be circumvented by using surveys or well-controlled experiments.

In this paper, we report a laboratory experiment on real options decisions. To our knowledge, this is the first exploratory study on the heterogeneity of intuitive real options strategies in a continuous-time setting. We would like to address the following questions: (1) Are our participants' intuitive strategies more consistent with NPV or real options strategies? (2) Are there different types of investors in our dynamic investment setting? (3) Can our participants identify the underlying price process and use it correctly for their decisions? (4) What are the potential behavioral pitfalls in such real options investment decisions?

Our participants were asked to imagine they are oil field managers. They observed the oil price in a simulated market, and had to decide on production technologies in each period. All changes of the production level incur switching costs. A real options strategy in this scenario would take into account the flexibility of investment decisions and switch less often than a NPV strategy.

The advantage of using experimental methods is that we can control the underlying price process and compute the optimal investment strategies based on various theoretical assumptions. Then the behavior of the participants can be compared with theoretical benchmarks, and we can identify different groups based on their implicit strategies. Using cluster analysis, we identified four typical strategies used by the participants, labeled as "Mean reverting," "Brownian motion real-option," "Brownian motion myopic realoption," and "ambiguous." The behavior of the first two groups was closest to the rational real options strategy under different assumptions of price processes (mean-reverting vs. Brownian motions). The last two groups played less optimal strategies - the third group behaved myopically without considering the termination of the game, whereas the last group played NPV strategy with a Geometric Brownian Motion process first, and converged to a mean-reverting strategy towards the end.

Some theorists observed that the intuitive investment decisions by managers are closer to real options strategies than the traditional NPV strategy (Dixit \& Pindyck 1994). Our results seem to support this observation, because the NPV strategy does not capture the behavior of most participants. However, we find two typical behavioral biases from our participants. First, many participants did not take into account the finite time horizon and switch 
too often at the end of the game, which reduced their earned profits. Second, although many participants expected a mean-reverting price process, they reacted to the price movement as if the price would follow a random walk, leading to too frequent switches.

Despite certain behavioral biases, some participants demonstrate certain kind of learning effect during the experiment. Two ways of learning are possible. The first way of learning is to increasingly behave according to the real options strategies over time. The second way of learning is to perceive the true underlying mean-reverting process, and incorporate this process into decision making. We found both types of learning among the participants.

The structure of the rest of the paper is as follows: in the second section we review the relevant literature on empirical and experimental option pricing and real options studies. In the third section we outline the theoretical framework behind our experimental design. The fourth section describes the experiment procedure and the results. In the last section we discuss the theoretical and practical implications of our study.

\section{Literature Review}

Before the formal introduction of the theoretical real options technique, many corporate managers and strategists have dealt with the ideas of managerial flexibility and strategic interactions on an intuitive basis. Myers (1977) first proposed the idea of thinking of discretionary investment opportunities as growth options. Kester (1984) discussed the strategic and competitive aspects of growth opportunities from a conceptual point of view. Other general aspects of real options framework have been developed by Mason \& Merton (1985), Trigeorgis \& Mason (1987), Trigeorgis (1988), Brealey \& Myers (1991), Kulatilaka (1988) and Kulatilaka (1992). More specific applications of the real options framework to various investment problems include real estate development (Titman 1985, Williams 1991), lease contracts (Schallheim \& McConnell 1983, Grenadier 1995), oil exploration (Paddock, Siegel \& Smith 1988), and research and development (Dasgupta \& Stiglitz 1980).

To our knowledge, there are relatively few experimental studies on option pricing and real options. In general, it seems that subjects tend to be inconsistent when they value options. For example, Shavit, Sonsino \& Benzion (2002) found that their subjects were risk-averse when assigning values to the basic lotteries, but risk-seeking when bidding options on the same lotteries. The bidding patterns also depends on the positions and initial endowments. Arbitrage opportunities are often unexploited in experimental option markets (Abbink \& Rockenbach 2006, OB́rien \& Srivastava 1993, Shavit et al. 
2002). Behavioral theories such as mental accounting (Rockenbach 2002) and Prospect Theory (Miller \& Shapira 2004) have been proposed to explain the inconsistent behavior regarding option valuations. However, the results by Shavit et al. (2002) can not fully be reconciled with Expected Utility Theory and Prospect Theory.

In particular, findings from previous experimental studies on real options are somehow mixed regarding whether people's intuition is consistent with real options theory. For example, there is evidence that the subjects take less irreversible investment now if they expect more information about the risky asset arrive in the future (Rauchs \& Willinger 1996). Howell \& Jägle (1997) asked managers to make hypothetical decisions on investment case studies in the context of growth options. In their setting, after a fixed period of time, it is possible to invest in a follow-up project. Several factors in the Black-Scholes model, such Present Value, volatility and time to maturity, have been varied to investigate whether respondents could intuitively apply real options approach. Although it seems that the respondents did not hold the simplistic NPV view for valuation, neither were their decisions perfectly in line with real options theory. Both under- and over-valuations occur. It is also observed that factors like industry, sector, personal experience and position have influences on valuations. Interestingly, more experienced managers were more likely to overvalue the projects, probably due to overoptimism. In general, the behavior of the respondents cannot be described by one model due to the existence of heterogeneity.

Another notable experimental study is from Yavas \& Sirmans (2005), who applied a simple two-stage investment setting to test for optimal timing by the subjects. They also measured the premium associated with the real options components of an investment and examined how this premium is correlated with uncertainty about future cash flows from the investment. Their results again provide mixed evidence regarding the descriptive validity of real options theory. On the one hand, most subjects seemed to be too optimistic and entered the project too early when compared with the theoretical optimal timing. On the other hand, in the bidding experiment, their bids for the right to invest in a project were in general close to the theoretical level, and reflected the value of the real options embedded in the project. Moreover, the bidding behavior of the participants was consistent with option pricing theory, which predicts that greater uncertainty about future cash flows increases the value of the project.

An interesting phenomenon in the experiment by Yavas \& Sirmans (2005) is the learning effect. At the beginning, the bids were too optimistic and hence too high, which is consistent with the typical observation that inexperienced investors tend to be more aggressive and optimistic. The price, 
however, converged to the theoretical predictions as the experience increases. There was also evidence that some subjects learned to postpone their investment decisions after they gained experience.

While the above studies are among the first empirical tests of option pricing theory, their set-ups are relatively simple. Subjects typically only make decisions over no more than three periods. Although simplified tasks help to disentangle confounding factors, it is not clear whether one can generalize the results to the more realistic context. This motivates us to start an experiment on real option investment in a highly dynamic environment, which is more complicated but also more realistic. Consistent with previous observations, we find real options strategies seem to be more intuitive than the NPV approach, but people differs very much in their strategies. We can categorize the subjects into four typical types. The behavior of some groups is consistent with some previous findings such as the learning effect and myopic behavior.

\section{Theoretical Model}

As a starting point, we established the theoretical framework for an oilmanager investment game, in which the players are supposed to choose between different oil-production technologies in a dynamic market setting in order to maximize their profits. In our setting, it is assumed that the exploration and development of the oil field have been finished, and the manager only encounters the decisions during the extraction stage. We have designed the exogenous underlying price process, and solved the optimal strategies as well as the optimal timing accordingly.

\subsection{NPV vs. Real Options}

Since for each period, players can make production decisions as a response to the current market price, the situation is comparable to a series of American call-options that can be exercised any time before the terminal date. The real-option approach can be applied in this scenario, which is different from the traditional NPV approach in that it takes the advantage of waiting. When using NPV as the criterion to evaluate the investment opportunity, one should invest immediately as long as the project has a positive net present value. In comparison, real options theory prescribes that it is sometimes better to wait until the uncertainty about the future cash flows are resolved. We calculated the optimal timing and the investment strategies for both NPV and real options approach as our theoretical benchmarks, as explained 
below.

\subsection{Geometric Brownian motion Process}

Geometric Brownian motion is among the most common continuous-time stochastic processes to model prices. A stochastic process $P_{t}$ is said to follow a Geometric Brownian motion if it satisfies the following equation:

$$
\mathrm{d} P_{t}=\mu P_{t} \mathrm{~d} t+\sigma P_{t} \mathrm{~d} W_{t}
$$

where $\left\{W_{t}, t \geq 0\right\}$ is a Wiener process or Brownian motion, and the constant parameter $\sigma$ represents variance or volatility. In our setting, the drift $\mu$ is equal to zero. The increments in $P$, i.e., $\Delta P / P$, are normally distributed, which means that absolute changes in $P$, i.e., $\Delta P$, are lognormally distributed, which is why the process has the name "geometric."

The following set defines the possible critical prices $S_{\text {crit }}$ where it is reasonable to change the technology (see Appendix A for the proof):

$$
\left\{\frac{-\frac{\alpha I}{T-u}+Q_{\text {old }} C_{\text {old }}-Q_{\text {new }} C_{\text {new }}}{Q_{\text {old }}-Q_{\text {new }}} \mid u \in[t, T], \alpha \geq 1\right\}
$$

where $Q$ denotes the quantity of production (e.g., the number of produced barrels of oil), and $C$ denotes the cost per unit (e.g., cost per barrel). The subscript old refers to the adopted technology at a given time period $t$. The subscript new stands for all other possible technologies other than the status quo. The numerator is a sum of two parts: the first part is the investment cost $I$ multiplied by a factor $\alpha$ and divided by the remaining time steps $T-t$, in which $T$ is the number of total periods and $t$ is the current period; the second part is the difference between the total production cost of the old and new technology. The denominator is the difference of the quantity of production from current technology and the alternative technology.

The real options strategy takes into account the uncertainty in the future and reevaluate the investment cost. That is, the investment cost $I$ is multiplied with the parameter $\alpha$, which reflects to which extent to the investor considers the future uncertainty. The larger the $\alpha$, the longer the player waits before switching. When $\alpha=1$, then it is equivalent to the NPV strategy. When $\alpha>1$, it corresponds to a possible real options strategy.

Figure 1 suggests such boundary solutions for a Geometric Brownian motion process. It shows the fluctuating price process and the switching boundaries that symbolize the critical price $S_{c r i t}$, where it is rational to switch from one production condition to another. The left panel indicates the solution for the NPV strategy $\alpha=1$ and the right panel shows the boundaries for 
the optimal real options strategy with $\alpha=30$. Compared to the real options strategy, it is clear that the boundaries for the NPV strategy are much narrower, triggering more frequent switches between production levels.

In our experimental setting, when assuming a Geometric Brownian process, a player would change technologies 38 times according to the NPV approach. It would cost $\$ 12300$ for technology changes, which almost offset the gross profit of $\$ 14071$, resulting in only a net profit of $\$ 1771$. In comparison, if an investor adopts the optimal real options strategy with $\alpha=30$, which theoretically would lead to maximum profits, then one only needs to change technologies 17 times. The net profit increases from $\$ 1771$ to $\$ 4689$, due to the reduction of switching costs.

Figure 1: Switching boundaries for NPV strategy $(\alpha=1$, left panel $)$ and a real-option strategy ( $\alpha=30$, right panel) with a Geometric Brownian Motion price process
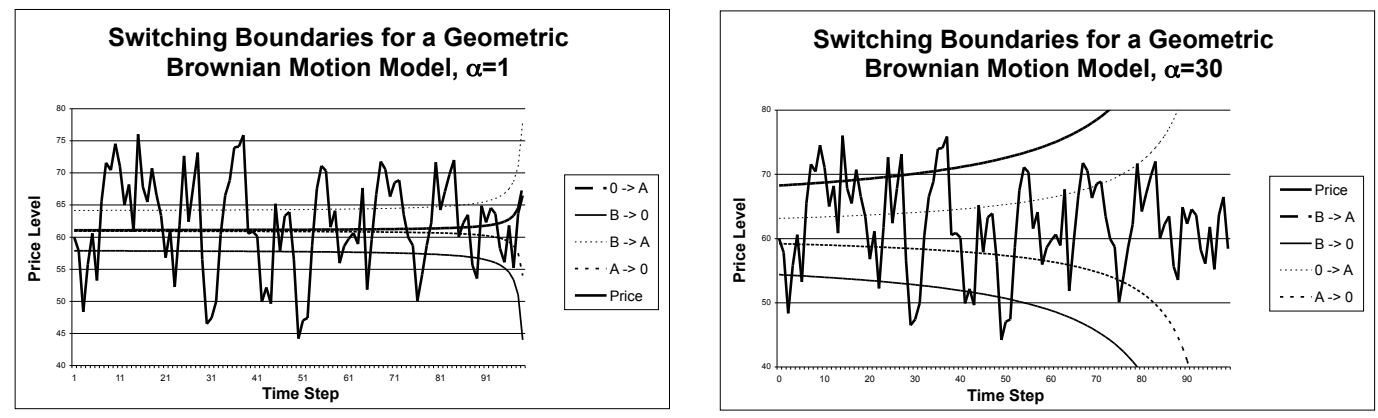

Notes: "A" denotes technology A, the technology with high production level and high cost; "B" denotes technology B, the technology with low production level and low cost; " 0 " denotes no production. "X $\rightarrow \mathrm{Y}$ " denotes switching from production $\mathrm{X}$ to production Y.

Another characteristic of the boundaries for the NPV strategy is that they are almost flat for the first ninety periods, and only spread at the very end. This means players should stop switching around the last ten periods because the switching costs are too high comparing to the limited expected profits. In comparison, the boundaries for the real options strategy spread out even earlier, implying that it is optimal to stop switching during the second half of the game. 


\subsection{Risk Aversion and Mean Reverting}

We now look at the boundary solutions for the more realistic assumptions, namely risk-averse attitude and mean-reverting process. Most real options models assume investors are risk-neutral, but in reality most investors are risk-averse. We can assume an exponential utility to capture the degree of risk-aversion as follows:

$$
u(x)=c e^{c x}
$$

where $c$ is the risk-aversion coefficient. Figure 2 shows a typical exponential utility function with $c=-0.0002$, which seems to fit the behavior of some types of our participants, as we will show later.

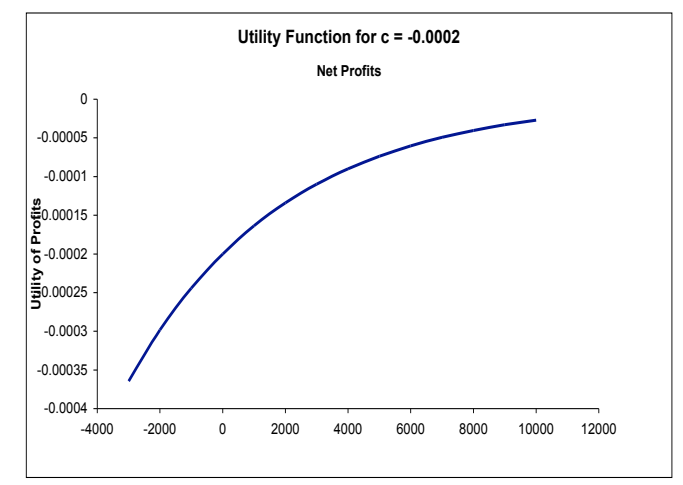

Figure 2: Exponential utility function $(c=-0.0002)$

Moreover, although Geometric Brownian motion as described above is frequently used to model economic and financial variables, such as interest rates and security prices, one may argue that it is more likely that oil prices in practice follow a mean-reverting price. As Lund (1993) points out, Geometric Brownian motion is hardly an equilibrium price process. The reason is that when the prices rise, there are incentives for existing firms to increase productions and for new firms to enter the market. The natural consequences are that the larger supply would slow down the price increase, and ultimately cause prices to decline. The same logic applies for the case of price decrease. Therefore, at the market level, mean-reverting process is a more plausible process for oil prices, which has been supported by some empirical tests (see e.g., Pindyck \& Rubinfeld (1991)). 
In our experiment, a mean-reverting process is used to model the stochastic behavior of the continuous-time oil prices. The oil price $P$ at time $t$ is:

$$
P_{t}=P_{t}^{D} e^{k\left(-\frac{Q_{t}^{\text {tot }}}{Q_{h, t}^{\text {max } x o t}}+0.5\right)}
$$

The above pricing process has two components, a mean-reverting component and an exponential one. The first component $P_{t}^{D}$ follows a meanreverting, or Orstein-Uhlenbeck process with

$$
d P_{t}^{D}=h\left(\mu-P_{t}^{D}\right) d t+\sigma d W_{t}
$$

where $\left\{W_{t}, t \geq 0\right\}$ is a Wiener process or Brownian motion, $\mu$ is the long-run mean of $P_{t}^{D}, h$ is the speed of adjustment, and $\sigma$ models the volatility of the process. In our experiment, $\mu=61.5, h=0.5, \sigma=9.0$, and $k=0$.

The second component in Equation 4 - the exponential function - models the supply side. The fraction in the exponent measures the production, which is the ratio between the realized industry production $\left(Q_{t}^{\text {tot }}\right)$ and the maximal industry production if all firms had chosen the technology with the high capacity $\left(Q_{t}^{\max , t o t}\right)$. The fraction has a co-domain of $[0,1] . k$ is a constant factor that determines the impact of the exponential on $P_{t}^{D}$. It is a proxy for the market size of the managed oil fields relative to the total market size. The higher the $k$, the bigger the impact of the supply on the price. When $k=0$, the oil price $P_{t}$ is determined independent of the oil production decisions by the market participants, which is the case in our experiment.

Appendix A provides the proof for the boundary solutions. Figure 3 shows the switching boundaries of NPV strategy (i.e., $\alpha=1$ ) for the meanreverting price process. The left panel shows the switching boundaries for the whole 100 time periods, whereas the right panel shows the boundaries for last 30 periods, so that one can see in more detail the boundaries towards the end. The boundaries become narrower over time but spread at the very end (the right panel). Indeed, with a mean reverting process there are less incentives to change the technology because the process is expected to revert to its equilibrium level and the expected profit generated by a change of technology could be negative. However, as time goes by, if the price becomes much higher than the equilibrium level and if the speed of adjustment is not too strong, the realized profit could be substantial because at maturity the price is expected to be high. Finally, when it is close to maturity, the sunk cost generated by a switch of technology is not compensated by possible profit. The boundaries spread at the very end because then it does not make sense to change the technology. In general, technology B (low production level) is the most profitable strategy, even for NPV strategy $(\alpha=1)$. This 
Figure 3: Switching boundaries for NPV strategy with a mean-reverting price process (Left panel: all 100 time steps; Right panel: step 70 to 100) $\mathrm{c}=-0.0002$
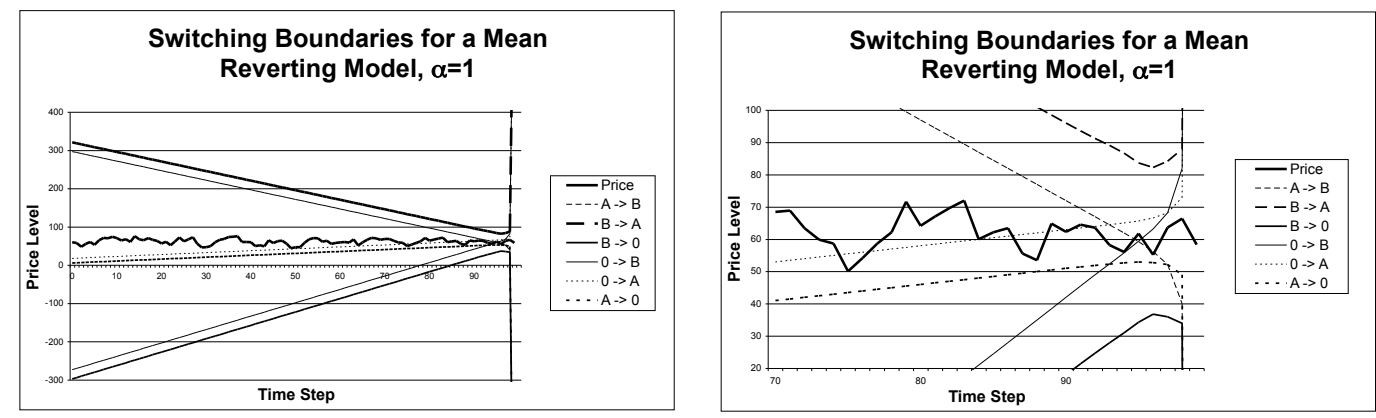

Notes: The left panel shows the boundary solutions the whole session (period $1 \sim 100$ ). The right panel shows the boundary solutions from period 70 to 100 , so one can see in more detail the solutions towards the end of the experiment. "A" denotes technology A, the technology with high production level and high cost; "B" denotes technology B, the technology with low production level and low cost; " 0 " denotes no production. "X $\rightarrow \mathrm{Y}$ " denotes switching from production $\mathrm{X}$ to production $\mathrm{Y}$.

is why in our setting one should never change the production technologies if she assumes a mean-reverting process, regardless of whether she adopts NPV or real options strategy.

\subsection{Brownian Motion (BM)}

When the speed of adjustment $h$ is equal to 0 in Equation 5, the process is consistent with a Brownian motion process. It can be considered as a continuous-time version of a random walk. It has the Markov property in that the past pattern of prices has no forecasting value, often referred to as "the weak form of market efficiency." It is based on the theoretical assumption that all public information is quickly incorporated in the current price and hence no investors could "beat the market."

Compared with the mean-reverting processes, the decision rules for Brownian motions are more explicit and intuitive. In principle, investors should start or increase production when the price rises above some threshold, and stop or reduce production when the price falls sufficiently. Figure 4 shows the boundaries for NPV and a real options strategy when $c=-0.0002$ in the exponential utility function (Equation 3). See Appendix A for the proof. 
Figure 4: Switching boundaries for real-option strategy with a Brownian price process and risk-aversion attitudes $(\mathrm{c}=-0.0002)$ (Left panel: NPV $\alpha=1$; Right panel: Real Option $\alpha=30$ )
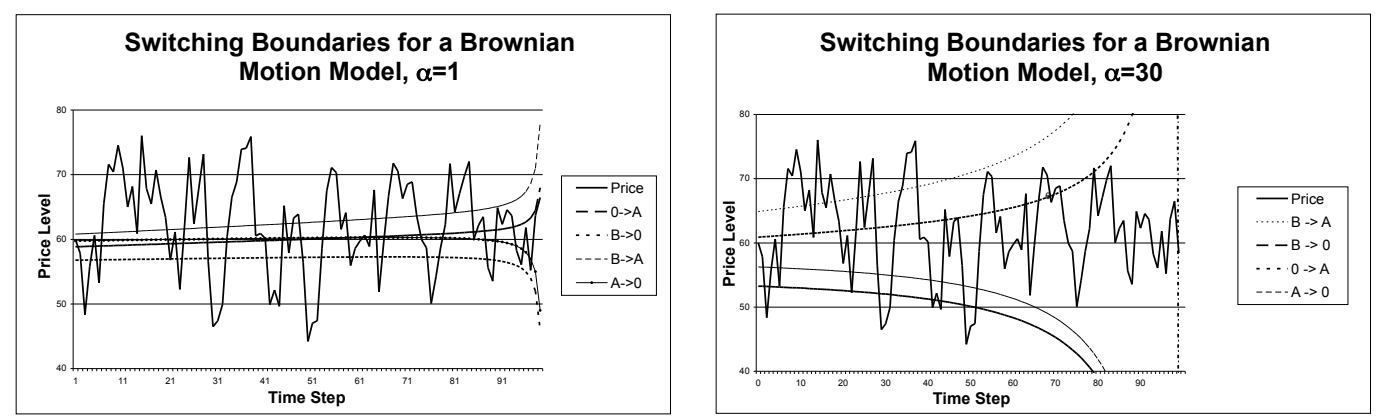

Notes: "A" denotes technology A, the technology with high production level and high cost; "B" denotes technology B, the technology with low production level and low cost; "0" denotes no production. "X $\rightarrow$ Y" denotes switching from production $\mathrm{X}$ to production Y.

\section{Experiment}

\subsection{Participants and Procedure}

In total 71 undergraduate students from the University of Zurich in Switzerland have participated the computerized experiment in June 2007. Our subject pool is relatively homogenous: They were recruited from classes in economics or finance. The majority was male students (only 7 participants were females). The average age was 24.4 years old (SD.=1.7). The data of five participants were removed due to invalid answers, resulting in 66 participants for the final analysis.

Figure 5 presents a screenshot of the experiment with illustrations, which is also included in the instruction sheet for each participant (see Appendix $\mathrm{B}$ for the text in the instruction sheet). In the experiment, participants were asked to play the role of an oil-field manager and run the oil field to maximize profits. For this purpose, they had to produce and sell oil in a simulated market. The oil price was generated from a mean-reverting Markov process, specified in Equation 4 and Equation 5 in the section of theoretical models. The price process is exogenous and the players are price takers, because we are mainly interested in investors' strategies but not the market equilibrium. The participants were not told the underlying price process, and all of them were confronted with the same price process.

The experimental session lasted 100 periods. Each period represents one 
business day and is divided into 10 sub-steps in order to approximate the daily dynamics generated by a stochastic process (e.g., Geometric Brownian motion or mean reverting). For simplicity, the oil cannot be reserved for the following periods, and all produced oil are automatically sold at the end of each period, and the players were asked to choose from two production technologies for the next period: (1) Technology A has a higher production level (50 barrels per day) and higher cost ( $\$ 61^{1}$ per barrel); (2) Technology $\mathrm{B}$ has a lower production level (25 barrels per day) and lower cost ( $\$ 58$ per barrel). Alternatively, a player could also choose to disinvest or shut down the production, resulting in zero production level. To switch between different technologies, or switching from zero level to a new technology costs $\$ 350$ each time, whereas switching between existing technology and disinvestment costs $\$ 300$ each time.

In addition to the production decisions, we also elicited participants' expectations of the price movement for each coming period. At the beginning of each period, before the participants see the price development of the coming period, they were asked to choose from three possible movements of the oil price: (1) the price will increase by more than $\$ 1$ from the previous period; (2) the price will decrease by more than $\$ 1$; (3) the price will stay more or less the same (i.e., less than $\$ 1$ change. The predictions were not incentivized.

Each participant was given 3000 experimental dollars as initial endowment (one experimental dollar $=0.005 \mathrm{CHF}$ ). Since the oil produced in each period is automatically sold at the current market price, the profit from each period is determined by (oil price - production cost) $\times$ (number of barrels) -(switching cost). The final profit is determined by the sum of the profit from all 100 periods. At the end of the experiment, the participants were paid out by cash based on their final profit which was converted to Swiss Francs (CHF). The whole experiment took about one hour, including an introduction session, an experimental session, and a questionnaire session. The average earning of the participants was 33.5 CHF ( $\mathrm{SD}=12.9 \mathrm{CHF})$.

The simulation also generated news messages of various events. There are two types of messages: relevant vs. irrelevant. The relevant messages make explicit predictions about the incoming oil price movement (i.e., increase/decrease/stay the same) based on certain events (e.g., workers in oil industry went on strike so that the oil price is expected to rise.), whereas the irrelevant messages report certain events unrelated to the oil market and have no obvious implication to short-term oil price fluctuations (e.g., the CEO of Apple announces plan for new Apple products). There are three treatments regarding incoming news messages: (1) Filtered information: participants

\footnotetext{
${ }^{1}$ The symbol $\$$ here represents experimental currency.
} 


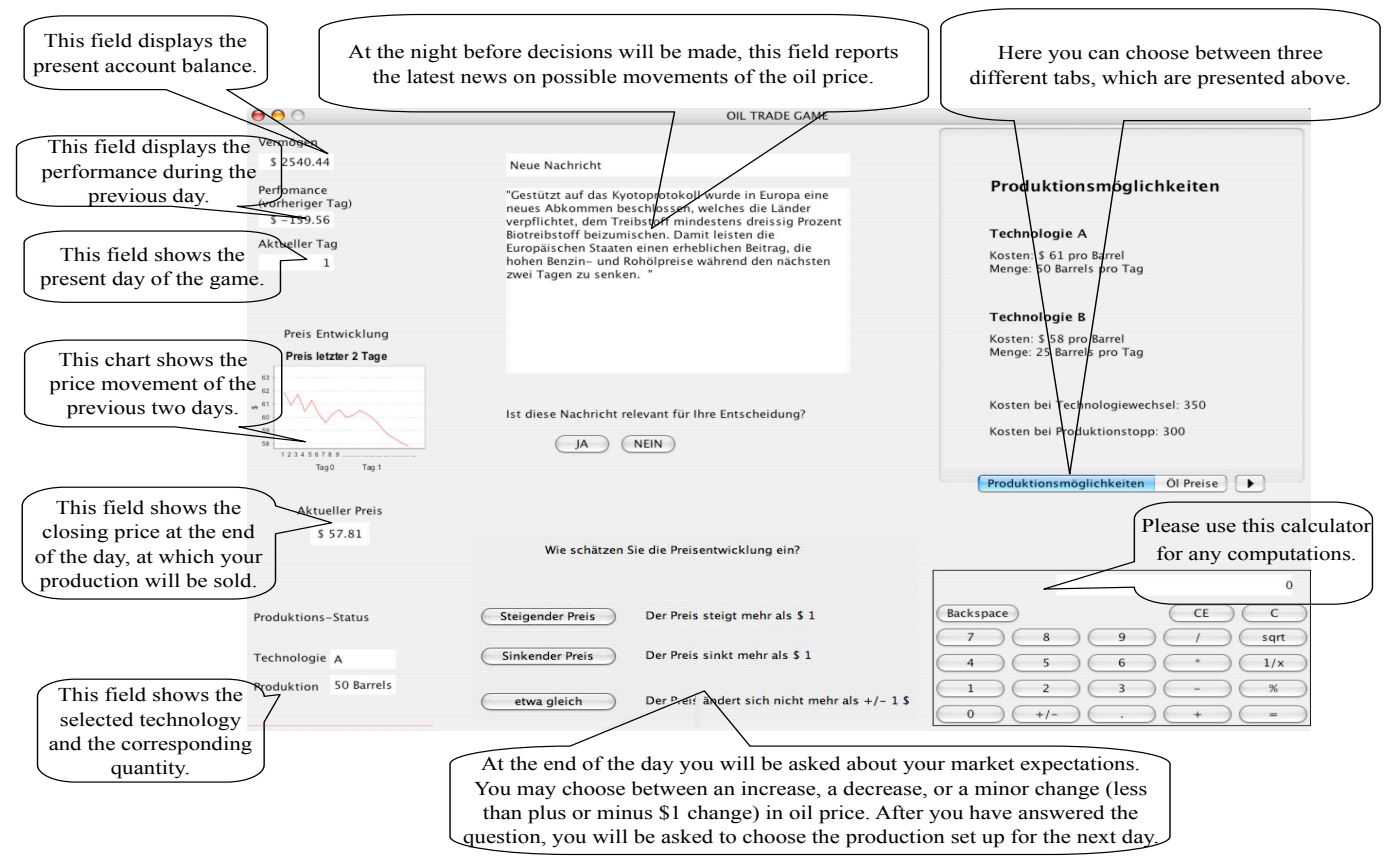

Figure 5: Screen shot in the instruction manual (the call-out boxes are translated into English from the original German texts ) 
only received relevant messages during 46 periods out of 100 periods; (2) All information: participants received a mixture of relevant and irrelevant messages during 70 periods out of 100 periods(with 46 periods of relevant messages and 24 periods of irrelevant messages); (3) No information: participants received no news messages during the whole experiment. We present the treatment effect in the following section.

\subsection{Treatment effect}

The purpose of the information treatment is to investigate (1) whether more information about price movement can improve the performance; (2) whether irrelevant information has negative impacts on performance. Table 1 shows the information treatment effects. The last column indicates that the group without information was indeed at disadvantage when they predicted the price movement in the next period: only around $32 \%$ of the time they predicted correctly the next period price movement, whereas the groups with information were more likely to predict correctly the price movement for the next period. The groups with information also performed better and made more profits. However, opposite to our expectation, the group with filtered information were slightly worse in prediction and performance when compared with the group with mixed information. It seems that irrelevant information did not hurt the performance. Moreover, the group with all information switched technologies less frequently than the other two groups. It is also interesting to see that although the group with filtered information switched approximately with same frequency as the group with no information, they performed significantly better, which implies that the group with filtered information were more efficient with their decisions.

Table 1: Switching frequencies, average profits and prediction hit ratios by each information treatment

\begin{tabular}{ccccc}
\hline & & Switching Frequencies & Mean Profits (\$) & Prediction hit ratio \\
Group & $\mathrm{N}$ & Mean(SD) & Mean(SD) & \\
\hline All information & 19 & $13.5(7.4)$ & $5439(2621)$ & $70.6(24.3)$ \\
Filtered information & 16 & $17.3(11.0)$ & $4846(2870)$ & $61.6(26.9)$ \\
No information & 31 & $19.2(7.0)$ & $3583(2677)$ & $31.7(14.1)$ \\
\hline
\end{tabular}

Note: ANOVA test shows marginally significant between-treatment differences on switching frequencies $(\mathrm{F}(2,63)=3.02, \mathrm{p}=0.05)$ and mean profits $(\mathrm{F}(2,63)=2.79, \mathrm{p}=0.06)$. Prediction hit ratio is defined by the proportion of correct prediction of oil price movement on the next period. We only calculated those periods with relevant messages. Paired t-tests indicate significant differences between treatments $(\mathrm{p}<0.01$ for all pair-wise comparisons). 


\subsection{Classification of participants based on strategies}

In order to classify participants based on their switching decisions, we run a two-step cluster analysis for all participants with all 100 periods. A two-step cluster method is a scalable cluster analysis algorithm to handle very large data sets. Unlike the K-means or hierarchical clustering, the two-step cluster method can handle both continuous and categorical variables. In our case, since the decision variables are categorical variables, the two-step cluster method is the only appropriate method. The log-likelihood distance measure and BIC criterion were used to detect the optimal number of clusters. The cluster analysis revealed four homogenous subgroups, which can be compared with candidate theoretical strategies.

Now let us look at the matching rate with the candidate strategies for each subgroup in Table 2. Each column represents one of the six potential strategies that have been discussed in the theoretical section, while each row represents one of the four types of investor from the cluster analysis. We compare the modal behavior of each cluster with the theoretical strategies. The matching rate is defined as the percentage of decisions that coincide with the theoretical strategies for the whole 100 periods. It seems that the first group matches very well (matching rate $=0.94$ ) with a NPV or real-option strategy when assuming a mean-reverting process. ${ }^{2}$ We label this group as "mean-reverting." The second group matches best with the optimal real options strategy under Brownian motion process with risk-averse attitude (matching rate $=0.87$ ). Thus they are labeled as "Brownian motion realoption." The third group, labeled as "Brownian motion myopic real-option," fits best with a myopic real-option strategy with risk averse attitude. The last group is most similar with NPV strategy with a Geometric Brownian motion process. However, later we will see that the last group behaved as if they changed the perceived price process from Geometric Brownian motion to Mean-reverting process. So it seems that this group did not follow a consistent strategy. Accordingly, we label them as "ambiguous ."

Figure 6 shows the majority behavior for each classified group as compared with the predicted decisions of the corresponding theoretical strategies. In the following we explain in more details these four strategies.

Group 1: "Mean-reverting" strategy. The left panel of the first row in Figure 6 shows the majority behavior of this group. Only nine out of our 66 participants belong to this cluster. Most of the time, technology B (low production technology) was chosen, which coincides with the theoretical NPV or

\footnotetext{
${ }^{2}$ Note that when assuming the mean-reverting process, both NPV and real options strategies would prescribe no changes and staying in Technology B. See discussion in the theoretical section.
} 
Table 2: Matching rates for each group with different strategies

\begin{tabular}{llcccccc}
\hline & & \multicolumn{4}{c}{ Risk-averse attitude } \\
& $\mathrm{N}$ & \multicolumn{2}{c}{ Geo. Brownian } & \multicolumn{4}{c}{ Mean-revert. } \\
Group & & NPV & RO & RO/NPV & NPV & RO & RO myopic \\
\hline 1. Mean-revert. & 9 & 0.47 & 0.08 & $\mathbf{0 . 9 4}$ & 0.26 & 0.08 & 0.08 \\
2. BM Risk-averse RO & 12 & 0.39 & 0.71 & 0.08 & 0.53 & $\mathbf{0 . 8 7}$ & 0.73 \\
3. BM Myopic RO & 29 & 0.46 & 0.73 & 0.07 & 0.55 & 0.67 & $\mathbf{0 . 7 5}$ \\
4. Ambiguous & 16 & $\mathbf{0 . 5 8}$ & 0.49 & 0.45 & 0.49 & 0.50 & 0.50 \\
\hline
\end{tabular}

Note: RO means Real Options and NPV means Net Present Value. Each row represents one of the four classified groups. Each column represents the potential strategies. Matching rate is the percentage of decisions that coincide with the theoretical strategies for the whole 100 periods for each group. For example, in the first row, 0.86 means that on average there are 86 periods out of 100 periods in which the decisions by participants in the mean-reverting group coincide with the theoretical predictions of NPV/Real options strategy for the mean-reverting price process. The bold fonts represent the highest matching rate among all theoretical strategies for a given group.

real options strategies when assuming the mean-reverting process (the right panel of the first row in Figure 6). One should avoid switching technologies under the mean-reverting process because the price will bounce back and it would not pay off to react to the short-run market price fluctuations. "Wait-and-see has the highest value in this case.

Group 2: "Brownian motion real-option" strategy. Twelve out of 66 participants are classified into this group (the second row in Figure 6). The main characteristic of their strategy is that they switched to the high-production technology when the oil price was sufficiently high, and shut down the production when the price was too low. When the game approached to the end, however, it was not worth to switch any more because the potential profit was limited. So the investors stayed at the high production level during the second half of the experiment. This behavioral pattern corresponds to a real-option strategy $(\alpha=30)$ under the assumption of Brownian motion price process and risk-aversion exponential utility function with the risk coefficient $\mathrm{c}=-0.0002$ (see the right panel in the second row).

Group 3: "Myopic Brownian motion real-option" strategy. This is the biggest group from our cluster analysis, which contains nearly half of the participants (29 out of 66). As we can see from the left panel of the third row in Figure 6, the participants basically followed the market price, i.e., switched to the high production when the price went up, and shut down the production when the price fell, which is very similar to the second group 
(real options with Brownian motion). The main difference is that the second group stopped switching during the second half of the game, whereas the third group still kept changing technologies, which is not optimal due to the high switching costs. This group played as if they ignored the finite horizon of the game and believed that the game would last for ever without a limit of potential profits. In this case, the theoretical switching boundaries are not sensitive to the termination date and keep flat until the last period. Therefore we call it a "myopic real-option" strategy assuming a Brownian motion process.

Group 4: "Ambiguous" strategy. The strategies adopted by the rest 16 participants are rather ambiguous (the last row in Figure 6). During the first 70 periods of the game, their decisions resemble a NPV strategy with an underlying Geometric Brownian Motion process - they switched to the high-production technology when the price is very high, reduced to the low production when the price is relatively low, and shut down when the price is very low. The changing frequency is substantially higher than the first three group. In the last 20 30 periods, the low production technology has been chosen and virtually no more switches occur, which is similar to a Meanreverting strategy (Group 1). We label this group as "ambiguous", because participants did not play consistently with one strategy. In contrast, they seemed to learn the underlying price process and changed their strategies over time. We will discuss this again in the next section about learning effect.

Table 3 shows the switching frequencies and average profits by each group with different strategies. It also shows the treatment effect within each group. We find that within the "Brownian motion myopic real-option" group, participants under either filtered or all information conditions perform better than those with no information $(\mathrm{p}<.05)$. Similar effect can be observed within the group who adopts the "Brownian motion real-option" strategy, although less significantly so $(\mathrm{p}=.06)$. Both groups suggest that participants seem to benefit from the information about price movements. It seems that the groups with "mean-reverting" and "ambiguous" strategies did not benefit from the information about price movements.

\subsection{Learning}

In the above we analyzed the matching rates for the whole experiment for all 100 periods. But it may happen that the participants learned to play more optimally over time. We divided the 100 periods into three windows - periods 1-33, 34-67, and 68-100. Figure 7 shows that in some cases the matching rates indeed change dramatically over time. The decisions by the second group match the "Brownian motion real option" strategy from around 
Figure 6: Four groups from cluster analysis

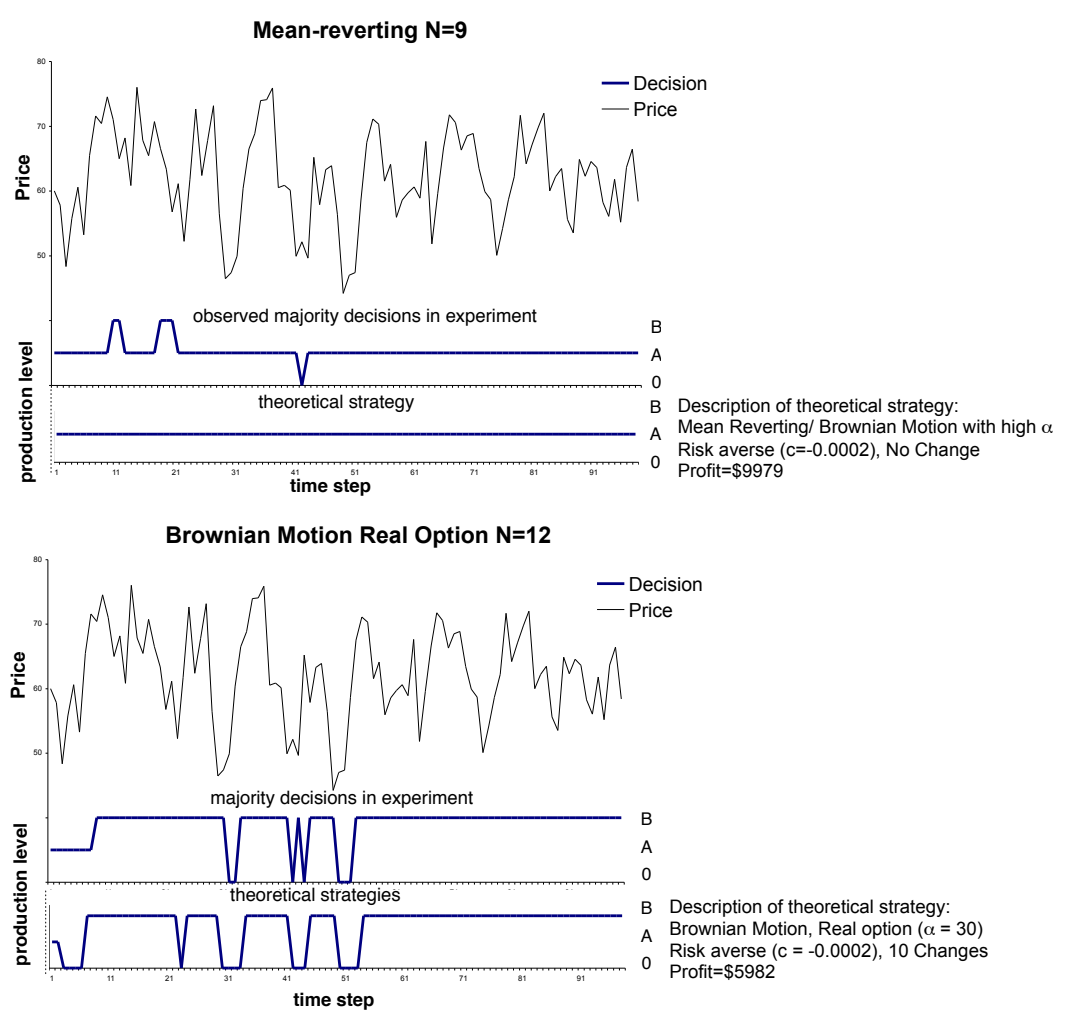

Brownian Motion Myopic Real Option N=29

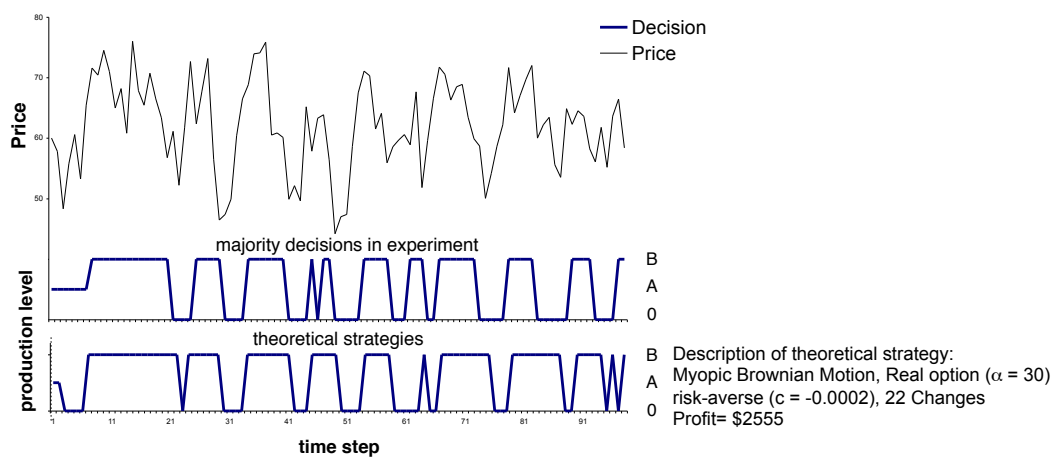

time step

Ambiguous, $\mathrm{N}=16$

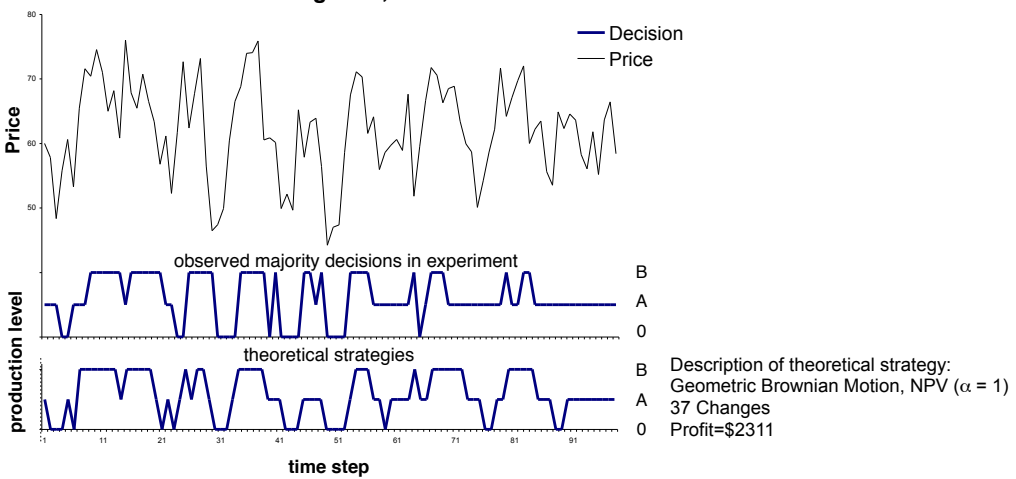

Note: The upper curve in each graph indicates the price process in the experiment. The two curves at the bottom in each graph indicate the observed majority production decisions in each cluster and the corresponding theoretical decisions, respectively. On the right side of the lowest curve, the assumptions and characteristics of each theoretical strategy are described. "A" represent high production level; "B" represents low production level. 
Table 3: Switching frequencies and average profits by each group and information treatment

\begin{tabular}{|c|c|c|c|c|c|}
\hline \multirow[b]{2}{*}{ Group } & \multirow[b]{2}{*}{$\mathrm{N}$} & \multicolumn{2}{|c|}{ Switching Frequencies } & \multicolumn{2}{|c|}{ Mean Profit (\$) } \\
\hline & & $\begin{array}{l}\text { Theoretical } \\
\text { prediction }\end{array}$ & $\begin{array}{l}\text { In experiment } \\
\text { Mean }(S D)\end{array}$ & $\begin{array}{l}\text { Theoretical } \\
\text { prediction }\end{array}$ & $\begin{array}{l}\text { In experiment } \\
\text { Mean(SD) }\end{array}$ \\
\hline Mean reverting & 9 & 0 & $9(6.6)$ & 9979 & 7756 (1909) \\
\hline Filtered information & 2 & & $14(5.7)$ & & $6081(1807)$ \\
\hline All information & 4 & & $6(5.3)$ & & $8857(978)$ \\
\hline No information & 3 & & $10(8)$ & & $7406(2469)$ \\
\hline ANOVA test & \multicolumn{3}{|c|}{$F(2,6)=1.26, p=.35$} & \multicolumn{2}{|c|}{$F(2,6)=1.77, p=.25$} \\
\hline Brownian motion $R O$ & 12 & 10 & $10(6.0)$ & 5982 & $4750(2383)$ \\
\hline Filtered information & 4 & & $7(3.8)$ & & $6401(1040)$ \\
\hline All information & 5 & & $10(6.2)$ & & $4908(1955)$ \\
\hline No information & 3 & & $14(7.0)$ & & $2284(2706)$ \\
\hline ANOVA test & \multicolumn{3}{|c|}{$F(2,9)=1.60, p=.25$} & \multicolumn{2}{|c|}{$F(2,9)=3.97, p=.06$} \\
\hline Brownian motion myopic $R O$ & 29 & 22 & $21(5.3)$ & 2555 & $3924(2390)$ \\
\hline Filtered information & 6 & & $21(5.5)$ & & $5465(2593)$ \\
\hline All information & 8 & & $17(4.0)$ & & $5047(1872)$ \\
\hline No information & 15 & & $23(4.9)$ & & 2708 (1988) \\
\hline ANOVA test & \multicolumn{3}{|c|}{$F(2,26)=4.36, p<.05$} & \multicolumn{2}{|c|}{$F(2,26)=5.33, p<.05$} \\
\hline Ambiguous & 16 & 37 & $20(9.6)$ & 2311 & $3211(2863)$ \\
\hline Filtered information & 4 & & $23(16.9)$ & & $1747(3165)$ \\
\hline All information & 2 & & $25(1.4)$ & & $1504(793)$ \\
\hline No information & 10 & & $18(6.6)$ & & $4138(2775)$ \\
\hline ANOVA test & & $F(2,13)=$ & $5, p=.50$ & $F(2,13)=$ & $=1.50, p=.26$ \\
\hline
\end{tabular}

Note: ANOVA test shows significant between-cluster differences on switching frequencies $(\mathrm{F}(3,62)=12.40, \mathrm{p}<0.01)$ and mean profits $(\mathrm{F}(3,62)=7.28, \mathrm{p}<0.01)$. The switching frequencies and mean profits of each information treatment subgroup are presented. ANOVA test shows no significant treatment effect except for "Brownian motion myopic real option" cluster.

$80 \%$ for the first 33 periods, and the matching rate increases to around $95 \%$ for the last 33 periods. We may say that this group seemed to learn to play optimal strategies as time went on.

The group with "ambiguous" strategy matches best with the real options strategy with Brownian motion or Geometric Brownian motion. However, in the last period, the matching rate with those strategies drops sharply, and there is a dramatic increase of matching rate with the strategies with mean-reverting process. They behaved as if they had identified the true underlying process, and incorporated this information in their decisions later in the game.

The biggest group, "Brownian motion myopic real-option" group, coin- 
cides best with the myopic real option strategy, without big differences across three time windows. This group switched between technologies until the end of the game, which is non-optimal.

\subsection{Expectations and decisions}

Although the true underlying price process in our experiment was a meanreverting process, the participants may have different perceptions. During the experiment, for each period we asked participants about their expectations of the price movement in the next period, which allows us to check the expected price process. In the following, we discuss the impact of current prices on expected future prices and production decisions. ${ }^{3}$

Figure 8 compares the price prediction vs. past period prices for all four groups. It is interesting to see that all four groups perceived some kind of mean-reverting underlying price process-- when the price in the previous period is high (low), they expected the price to go down (up) in the next period. For the middle-range prices, they expected little change in the next period. ${ }^{4}$

Figure 9 shows that in general, for the high prices, they tended to use high production technology; for the medium prices, they tended to use low production technology. When the prices were sufficiently low, they tended to have no production. This is puzzling because according to our comparisons with the theoretical strategies, most participants behaved "as if" they believed in a Brownian motion price process, but they seem to perceive a mean-reverting process based on our elicitation of their expectations. In other words, they somehow expected the future price will revert to the average price, but they did not incorporate this information into their decisions. Further analysis on the relation between prices and switching decisions indicates that the decisions to switch to higher production levels tend to occur when the prices were relatively high $($ Mean $=63.0, \mathrm{SD}=7.4, \mathrm{~N}=621)$, whereas decisions to reduce production levels tend to occur when prices were relatively low (Mean=58.8, $\mathrm{SD}=7.9, \mathrm{~N}=573)$. This implies that some participants switched production

\footnotetext{
${ }^{3}$ We have conducted regression analysis to see whether the current performance affect decisions. We find that the decisions are very sensitive to the current price but not to current wealth level or performance. It seems that in our settings, participants paid more attention to the price fluctuation than the recent performance. Therefore we couldn't observe strong recency effects based on recent experience and payoffs as suggested from the previous literature (Denrell 2007, Erev, Ert, Roth, Haruvy, Herzog, Hau, Herwig, Steward, West \& Lebier 2010, Ert \& Erev 2007, Marchiori \& Warglien 2008, Odean 1999).

${ }^{4}$ Such central tendency of judgment has also been reported in the classic literature by Hollingworth (1910) and Helson (1964).
} 
Figure 7: Matching strategies over time for four groups
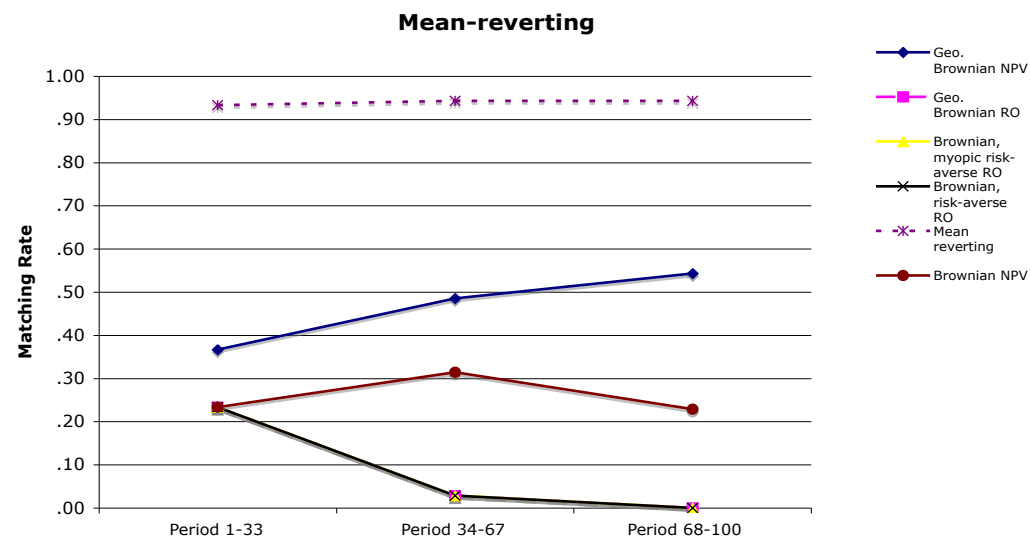

Brownian Motion Risk-Averse Real Option
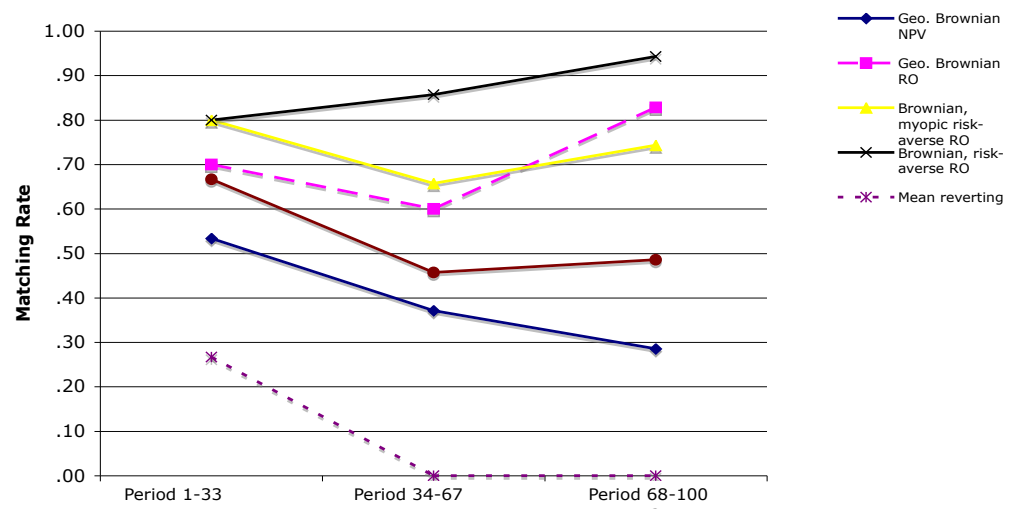

Brownian Motion Risk-Averse Myopic Real Option

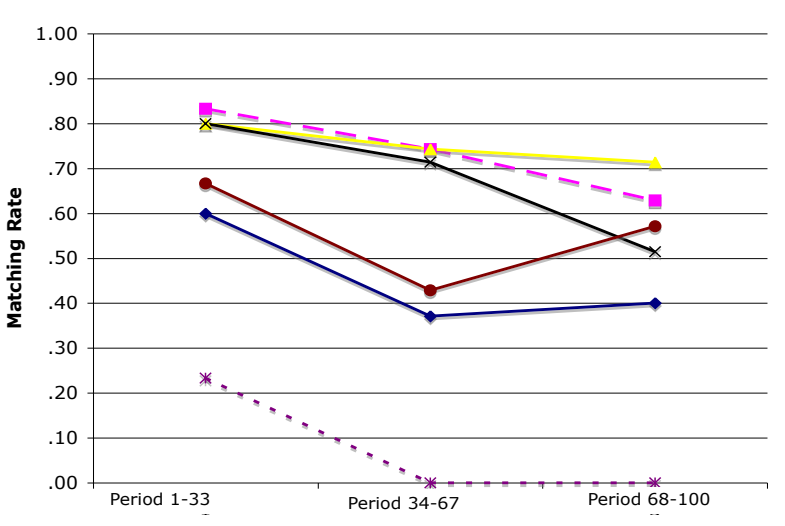

$\longrightarrow$ Geo. Brownian

- - Geo. Brownian

Brownian,
myopic risk-
averse RO averse RO
Brownian, risk-

Brownian, $r$ averse RO

-*- - Mean reverting

Ambiguous Strategy

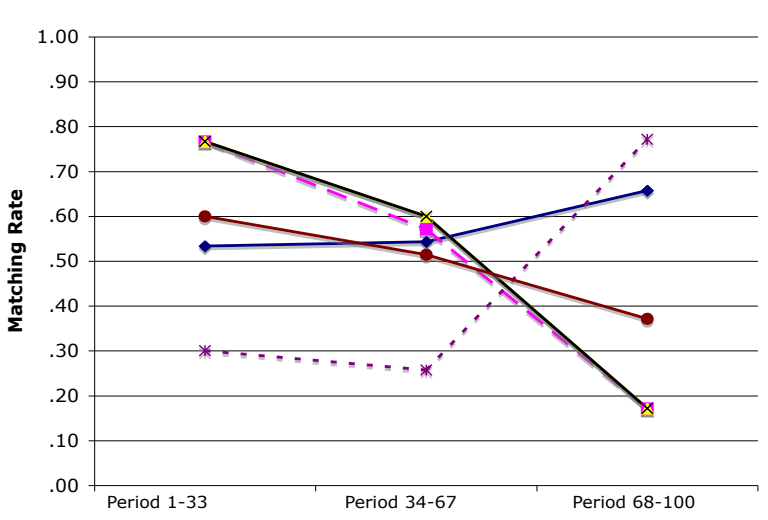

$\longrightarrow$ Geo. Brownian NPV

- Geo. Brownian, RO Brownian, myopic * Brownian, risk- -*- - Mean reverting $\longrightarrow$ Brownian NPV 
technologies as an immediate response to the market price fluctuation without considering the switching cost. Their production decisions were more in a trend-following style, which is opposite to their mean-reverting belief. It contradicts the normative point of view, because if investors believed the price will revert to some mean price, they should have waited longer for price to bounce back and should not change the technologies so quickly, since potential profits would be too low to compensate the switching costs.

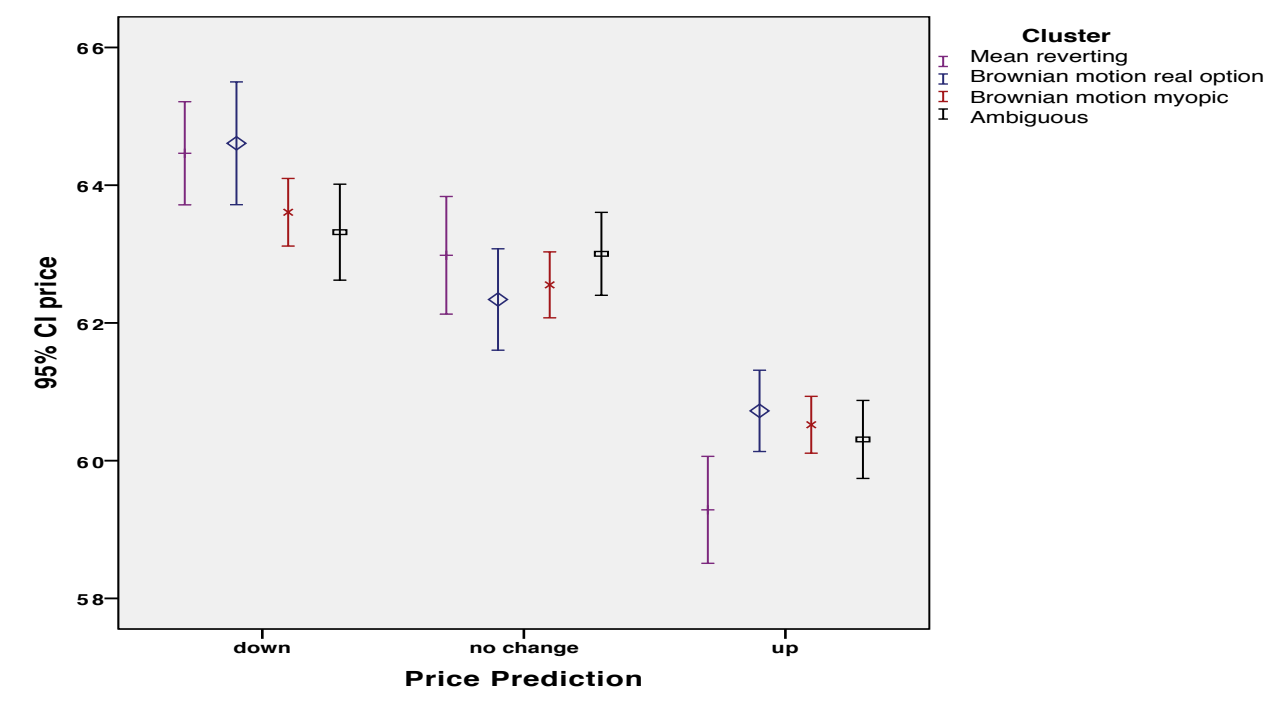

Figure 8: Price prediction vs. past price for all four groups

Note: The $x$-axis shows the prediction of price movement for the coming period $t+1$ and the $y$-axis shows the $95 \%$ Confidence Interval (CI) of the price in the current period $t$.

\subsection{Information, price perception, and strategies}

Figure 10 shows the range of past period price as compared to price prediction for different information conditions. As we expected, the group with no information perceive the price process to be close to a Brownian motion process, whereas the groups with filtered information and unfiltered information perceive the price to be closer to the true price process (mean-reverting process).

Figure 11 shows that the subjects with information were more likely to choose the more profitable strategies, and belong to the "more rational" groups ("mean reverting" and "Brownian motion real-option"), whereas the subjects without information were more likely to be classified into the "less rational" groups ("Brownian motion myopic real-option" and "ambiguous"), 


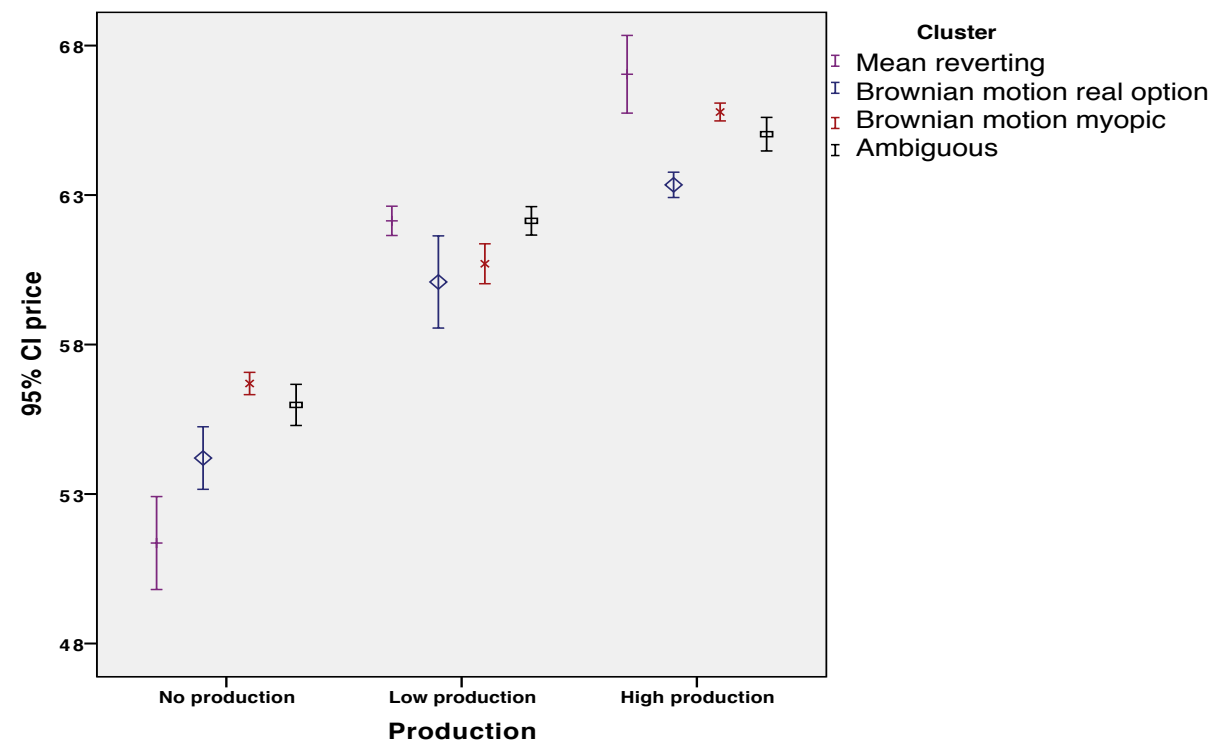

Figure 9: Production decision vs. past period price for all four groups

Note:The $x$-axis shows the decisions for production level for the coming period $t+1$ and the $y$-axis shows the $95 \%$ Confidence Interval (CI) of the price in the current period $t$.

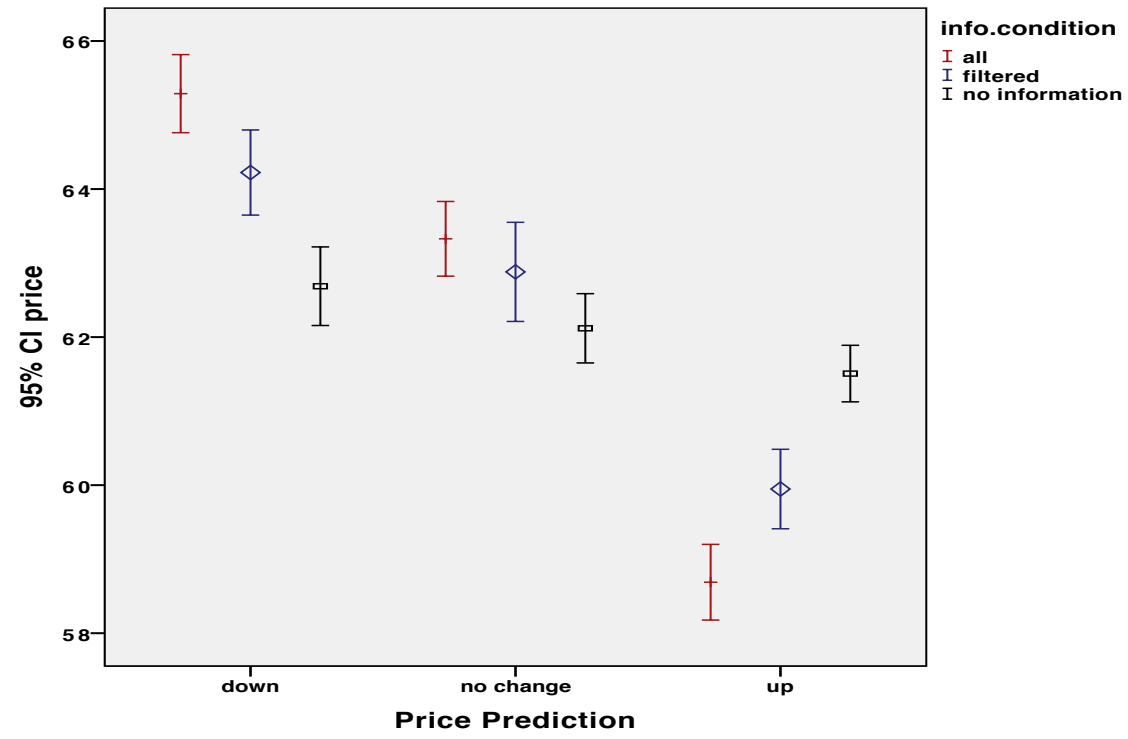

Figure 10: Price predictions vs. past period price across different information conditions

Note: The $x$-axis shows the prediction of price movement for the coming period $t+1$ and the $y$-axis shows the $95 \%$ Confidence Interval (CI) of the price in current period $t$. 
who followed less optimal strategies. However, the differences are only significant for the "Brownian motion real-option" group $(\mathrm{p}=0.004)$ and marginally significant for the "ambiguous group" $(\mathrm{p}=0.07)$. The lack of statistical power can be caused by the small sample size. Further studies are needed to investigate the mechanisms under which the strategies are influenced by available information.

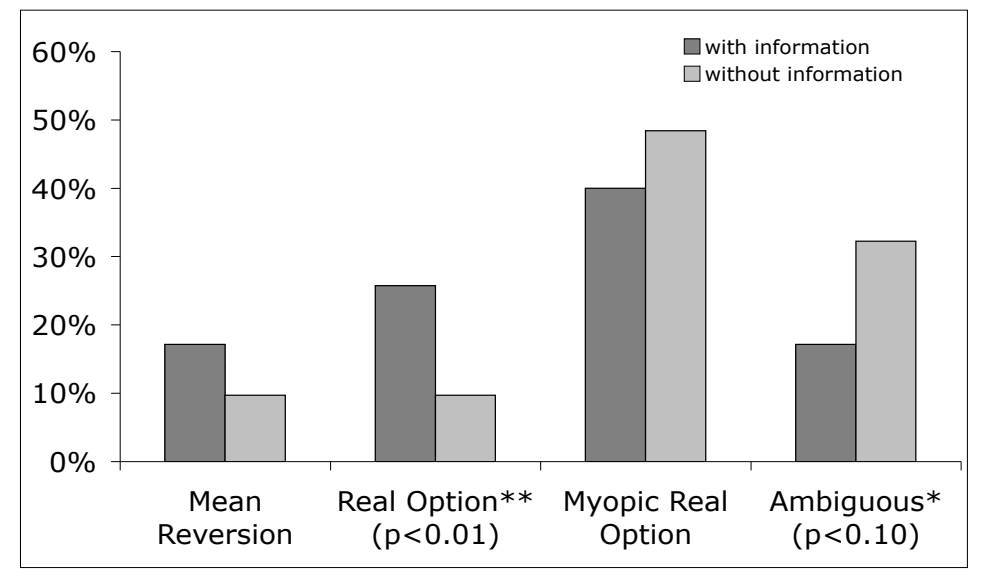

Figure 11: Group classification within information conditions

Note:

1. The difference between the full information and the filtered information conditions are not significant. The $t$-test results for each cluster are: Mean reversion $(t=0.685$, $\mathrm{p}=0.25)$, Real option $(\mathrm{t}=0.089, \mathrm{p}=0.54)$, Myopic real option $(\mathrm{t}=0.278, \mathrm{p}=0.39)$,Ambiguous $(\mathrm{t}=1.121, \mathrm{p}=0.14)$. Therefore we pool these two group and label it as "with information." 2. The t-tests results between the groups with and without information are: Mean reversion $(\mathrm{t}=0.900, \mathrm{p}=0.81)$, Real option $(\mathrm{t}=1.763, \mathrm{p}=0.004)$, Myopic real option $(\mathrm{t}=0.687$, $\mathrm{p}=0.25)$, Ambiguous $(\mathrm{t}=1.434, \mathrm{p}=0.07)$.

\section{Conclusion}

This paper reports a laboratory experiment to test how people intuitively handle option-like investment. It can be seen as an extension of previous experimental studies on real options in the literature, e.g., Yavas \& Sirmans (2005), Miller \& Shapira (2004) and Howell \& Jägle (1997). We use 
continuous-time setting which is closer to decisions in the real world. Although we did not recruit real managers for our tasks, our student subjects were mostly with economic or finance backgrounds, and were very interested in such management tasks. In a questionnaire at the end of the experiment, most participants indicated that they found the experiment interesting, and they also indicated that maximizing payoffs is one of their main goals. Therefore, we believe the students were well motivated.

Although many people may believe managers and professionals are rational and can perform better than students and laymen, numerous empirical studies show that professionals also prone to various kinds of behavioral biases, e.g., Cadsby \& Maynes (1998), Gort, Wang \& Siegrist (2008). It was also found in laboratory experiments that professional traders even performed worse than university students in the option pricing tasks (Abbink \& Rockenbach 2006), and CEOs behaved similarly to undergraduates in the bubble experiments (Ackert \& Church 2001), etc. In general, the literature on experimental economics and finance suggests no significant differences between university students and professionals in such stylized experiments (Ball \& Cech 1996, Banks, Camerer \& Porter 1994, King, Smith, Williams \& van Boening 1992, Siegel \& Harnett 1964). The behavioral biases found in our experiment, therefore, may not be unique only for undergraduate samples. The experimental and empirical studies are complementary in the sense that the observed behavior from well-controlled experiments offers us guidance regarding what kinds of behavioral biases we should look for when studying real-world decisions. The further step is to compare the behavioral patterns revealed in our experiment with the real-options investment behavior by professionals, and to study the implications of such biases on option pricing at the aggregate level through theoretical modeling.

Different types of investment behavior among players were identified using cluster analysis. We found some participants behaved close to optimal real options strategies, whereas others exhibited certain typical behavior biases. This is consistent with the general findings on "typing" heterogeneous behavior in dynamic decision problems, such as Bayesian learning (El-Gamal \& Grether 1995) and stochastic sequential discrete choice (Houser, Keane \& McCab 2004). Our results can shed lights on understanding the different types of intuitive strategies when it comes to real options investment.

The first behavioral bias we noticed is the ignorance of mean-reverting process. Most participants seemed to believe in a mean-reverting price process. However, many of them did not incorporate this expectation into their decisions, and hence switched technologies by following the market price as if they believed in a Brownian motion process. Although it is extremely difficult to determine the true process in reality, ignoring mean-reversion may 
undervalue the value of a project (Dixit \& Pindyck 1994). In particular, not being able incorporating the expected price process into decision making like our participants, may be a more general behavioral bias that deserves further investigation.

Another bias we found is the insensitivity to the termination date. Nearly half of our participants played as if the game would last for ever. They kept switching technologies till the end of the experiment, a strategy that would not pay off due to the high switching cost and low limited expected profits. However, some participants seemed to learn over time. In the future, it is important to investigate under which conditions investors can learn faster, and how they learn.

In general, it seems that the real options approach with a Brownian motion process make more intuitive sense to most participants than the NPV approach, even though they inclined to certain kinds of biases like described above. It is important to document the heterogeneity and understand which factors can cause such different behavior, an under-explored topic. In our experiment, the participants were not told the underlying price process. Instead we provided some participants with news messages that predict the future price movements, and other participants without such messages. We also elicited their own predictions at the end of each period. However, these are rather indirect measures which potentially add unnecessary noise. In the future experiments, the design can be improved by instructing the participants about the precise underlying price processes, e.g., mean-reverting process vs. Brownian-motion process, and compare the differences, e.g., whether people adjust their strategies based on different underlying processes.$^{5}$

In our experiment, the investors made decisions at the individual level without interactions to other players. But in reality the optimal strategies also depend on the market environment, e.g., the degree of competition - the advantage of waiting may be reduced when competition is intense. Moreover, the possibilities of alliance can also influence the optimal strategies. One possible extension to the experimental setting is to introduce such interactions between players (for a review on games and real options, see Smit \& Trigeorgis (2006)). Such interactive setting would help us to gain insights not only on individual decisions on real options investment under alliance and competition, but also on the evolution process of market equilibriums.

We hope our study takes one further step in developing a descriptive real options theory, and we encourage more in-depth empirical and experimental research on real options to understand how managers learn, how they integrate information, and how they react to competition and alliance.

\footnotetext{
${ }^{5}$ We thank an anonymous referee for this point.
} 


\section{Acknowledgements}

We thank Raphael Jordan, Tobias Ganz, and Maxim Litvak for the technical supports on experiments and data analysis. We also thank two anonymous referees for their comments. Financial supports by the National Centre of Competence in Research "Financial Valuation and Risk Management" (NCCR FINRISK), Project 3, "Evolution and Foundations of Financial Markets", the Research Priority Program "Finance and Financial Markets" at the University of Zürich, and the Richard Büchner Foundation are gratefully acknowledged.

\section{A Proof of Boundary Conditions}

\section{A.1 Geometric Brownian Motion}

In the case of Geometric Brownian Motion, the dynamics of oil prices are given by:

$$
\frac{\mathrm{d} P_{u}}{P_{u}}=\sigma \mathrm{d} W_{u}
$$

where the constant parameter $\sigma$ represents the volatility. In this setting, the drift is equal to zero. The discount rate is the constant parameter $r$.

\section{A.1.1 NPV approach}

The expectation of the discounted profit $\Pi_{t}$ corresponding to a switch of technology at time $t$ (from the old one to a new one) is:

$$
\mathbb{E}_{\mathbb{P}}\left(\Pi_{t} \mid \mathcal{F}_{t}\right)=\left(\mathbb{E}_{\mathbb{P}}\left[\int_{t}^{T} P_{u} e^{-r(u-t)} \mathrm{d} u \mid \mathcal{F}_{t}\right]-C_{\text {new }}(T-t)\right) Q_{\text {new }}-I
$$

where $I$ represents the switching cost, from the old to the new technology, i.e.

$\mathbb{E}_{\mathbb{P}}\left(\Pi_{t} \mid \mathcal{F}_{t}\right)=\left(\mathbb{E}_{\mathbb{P}}\left[P_{t} \int_{t}^{T} e^{-r(u-t)} e^{-\frac{-\sigma^{2}}{2}(u-t)+\sigma\left(W_{u}-W_{t}\right)} \mathrm{d} u \mid \mathcal{F}_{t}\right]-C_{\text {new }}(T-t)\right) Q_{\text {new }}-I$

The experiment lasts only a few hours, therefore we assume that the interest rate $r$ is equal to zero. In order to approximate the exercise boundary, we assume that the new technology will be kept up until maturity $\mathrm{T}$. 
$\mathbb{P}$ represents the historical probability. The following result is obtained:

$$
\mathbb{E}_{\mathbb{P}}\left(\Pi_{t} \mid \mathcal{F}_{t}\right)=Q_{\text {new }}(T-t)\left(P_{t}-C_{\text {new }}\right)-I
$$

In order to obtain the critical price $P^{*}$, the expected discounted profit, in the case of technology change, has to be compared with the expected discounted profit if the firm keeps the old technology. This critical price satisfies therefore the following equation:

$$
Q_{\text {new }}(T-t)\left(P_{t}^{*}-C_{\text {new }}\right)-I=Q_{\text {old }}(T-t)\left(P_{t}^{*}-C_{\text {old }}\right)
$$

and expression 2 is obtained, with $\alpha=1$. This case corresponds to the NPV approach.

\section{A.1.2 The real options approach}

In this setting, the players will wait longer before switching. Therefore we obtain a set of possible exercise boundaries:

$$
\left\{\frac{-\frac{\alpha I}{T-u}+Q_{\text {old }} C_{\text {old }}-Q_{\text {new }} C_{\text {new }}}{Q_{\text {old }}-Q_{\text {new }}} \mid u \in[t, T], \alpha \geq 1\right\}
$$

which corresponds to expression 2. In order to derive the optimal parameter $\alpha^{*}$, we rely on a Monte-Carlo simulation. The price process is simulated $n$ times and we look for $\alpha$ which maximizes the average realized profit.

\section{A.2 The mean reverting process}

In this case, we focus on an Orstein-Uhlenbeck process. The dynamics of oil prices are therefore given by:

$$
\mathrm{d} P_{t}=h\left(\mu-P_{t}\right) \mathrm{d} t+\sigma \mathrm{d} W_{t}
$$

We work with the following utility function:

$$
U(x)=c e^{c x}
$$

where $\mathrm{c}$ is a negative parameter.

The expected utility of the profit $\Pi_{t}$ corresponding to a switch of technology at time $t$ is:

$$
\mathbb{E}_{\mathbb{P}}\left(U\left(\Pi_{t}\right) \mid \mathcal{F}_{t}\right)
$$


where

$$
\Pi_{t}=Q_{\text {new }}\left(\int_{t}^{T} P_{u} \mathrm{~d} u-C_{\text {new }}(T-t)\right)-I
$$

Therefore:

$$
\begin{gathered}
\mathbb{E}_{\mathbb{P}}\left(U\left(\Pi_{t}\right) \mid \mathcal{F}_{t}\right)=\mathbb{E}_{\mathbb{P}}\left(e^{c Q_{\text {new }} \int_{t}^{T} P_{u} \mathrm{~d} u} \mid \mathcal{F}_{t}\right) \times e^{-c C_{\text {new }} Q_{\text {new }}(T-t)} \times e^{-c I} \\
=e^{c Q_{\text {new }} M(t, T)+\frac{c^{2}}{2} Q_{\text {new }}^{2} V(t, T)} \times e^{-c C_{\text {new }} Q_{\text {new }}(T-t)} \times e^{-c I}
\end{gathered}
$$

with:

$$
\begin{gathered}
M(t, T)=\mu(T-t)+\left(P_{t}-\mu\right)\left(\frac{1-e^{-h(T-t)}}{h}\right) \\
V(t, T)=-\frac{\sigma^{2}}{2 h^{3}}\left(1-e^{-h(T-t)}\right)^{2}+\frac{\sigma^{2}}{h^{2}}\left(T-t-\frac{1-e^{-h(T-t)}}{h}\right)
\end{gathered}
$$

Indeed, $\int_{t}^{T} P_{u} \mathrm{~d} u$ is a normally distributed random variable with mean $M(t, T)$ and variance $V(t, T)$.

In order to obtain the exercise boundary, the expected utility of the profit with the new and the old technology, have to be compared. $P_{t}^{*}$ is the solution of the following equation:

$$
\begin{array}{r}
e^{c Q_{\text {new }} M(t, T)+\frac{c^{2}}{2} Q_{\text {new }}^{2} V(t, T)} e^{-c C_{\text {new }} Q_{\text {new }}(T-t)-c I}= \\
=e^{c Q_{\text {old }} M(t, T)+\frac{c^{2}}{2} Q_{\text {old }}^{2} V(t, T)} e^{-c C_{\text {old }} Q_{\text {old }}(T-t)}
\end{array}
$$

i.e.

$$
\begin{aligned}
\left(Q_{\text {old }}-Q_{\text {new }}\right) M(t, T)=-\frac{c}{2}\left(Q_{\text {old }}^{2}-Q_{\text {new }}^{2}\right) V(t, T)+(T-t)\left(Q_{\text {old }} C_{\text {old }}-Q_{\text {new }} C_{\text {new }}\right)-I \\
\begin{aligned}
\left(Q_{\text {old }}-Q_{\text {new }}\right)\left(P_{t}-\mu\right)\left(\frac{1-e^{-h(T-t)}}{h}\right) & =-\frac{c}{2}\left(Q_{\text {old }}^{2}-Q_{\text {new }}^{2}\right) V(t, T)- \\
& -I+(T-t)\left(Q_{\text {old }} C_{\text {old }}-Q_{\text {new }} C_{\text {new }}\right)- \\
& -\left(Q_{\text {old }}-Q_{\text {new }}\right) \mu(T-t)
\end{aligned}
\end{aligned}
$$

i.e.

$$
\begin{aligned}
P_{t}^{*}= & \mu+\frac{h}{1-e^{-h(T-t)}}\left[-\frac{c}{2}\left(Q_{\text {old }}^{2}-Q_{\text {new }}^{2}\right) V(t, T)-I+\right. \\
& \left.+\left(Q_{\text {old }} C_{\text {old }}-Q_{\text {new }} C_{\text {new }}\right)(T-t)-\left(Q_{\text {old }}-Q_{\text {new }}\right) \mu(T-t)\right] /\left(Q_{\text {old }}-Q_{\text {new }}\right)
\end{aligned}
$$


In the real options setting, there is a set of possible exercise boundaries:

$$
\begin{aligned}
& \left\{\mu+\frac{h}{1-e^{-h(T-t)}}\left[-\frac{c}{2}\left(Q_{\text {old }}^{2}-Q_{\text {new }}^{2}\right) V(t, T)-\alpha I+\right.\right. \\
& \left.\quad+\left(Q_{\text {old }} C_{\text {old }}-Q_{\text {new }} C_{\text {new }}\right)(T-t)-\left(Q_{\text {old }}-Q_{\text {new }}\right) \mu(T-t)\right] /\left(Q_{\text {old }}-Q_{\text {new }}\right), u \in[t, T], \alpha \geq 1
\end{aligned}
$$

The exercise boundary corresponds to the value of $\alpha$ which maximizes the average realized profit. The NPV case is obtained for $\alpha=1$.

\section{A.3 The Brownian motion}

In this case the dynamics of the underlying are given by:

$$
\mathrm{d} P_{t}=\sigma \mathrm{d} W_{t}
$$

The exercize boundary is obtained by letting $\mathrm{h}$ going to zero in the last equation.

By relying on a Taylor expansion, we obtain the following set of possible exercise boundaries:

$\left\{\frac{\left(Q_{\text {old }} C_{\text {old }}-Q_{\text {new }} C_{\text {new }}\right)-\frac{\alpha I}{T-u}-\frac{c}{3}\left(Q_{\text {old }}^{2}-Q_{\text {new }}^{2}\right) \sigma^{2}(T-t)^{2}}{Q_{\text {old }}-Q_{\text {new }}} \mid u \in[t, T], \alpha \geq 1\right\}$

\section{B Instruction sheet of the Experiment}

\section{Introduction}

- This experiment investigates human behaviour under uncertainty. The participants are rewarded according to their achievements.

- During the experiment, it is not allowed to communicate with other participants or to look at their screens.

- The experiment is to be processed to the full extent.

- If the participant does not follow the above rules, he or she will be excluded from the experiment without getting paid

\section{The structure of the experiment}

- You play the role of the oil company manager and choose the technology which allows you to extract a certain quantity of oil and later sell it on the market. 
- Each time period in the experiment corresponds to a day on the oil market. Overall, the experiment lasts for 100 days.

- Every day you observe the price on the oil market. In the evening, after the market is closed, you will be first asked about your expectations on the tomorrow. Only then you can decide on your production setup for the next day.

- You begin with the starting capital of $3000 \$$. If you go bankrupt, you will be fired and the experiment is finished for you. The higher wealth you achieved, the more you get paid.

- You can choose between 2 technologies with following parameters:

\begin{tabular}{|r|c|l|}
\hline Name & Costs per barrel & $\begin{array}{l}\text { Production } \\
\text { per day }\end{array}$ \\
\hline Technology A & 61 Dollar & 50 Barrel \\
\hline Technology B & 58 Dollar & 25 Barrel \\
\hline
\end{tabular}

- Every technology change causes the switching costs. A technology change costs $350 \$$, a production stop costs $300 \$$. If you start producing again with the same technology, you need to pay $300 \$$, if you change technology after the stop, you need to pay $350 \$$ for it.

\begin{tabular}{|l|c|}
\hline $\begin{array}{l}\text { Switching costs from A to B or from B } \\
\text { to A }\end{array}$ & $350 \$$ \\
\hline $\begin{array}{l}\text { Switching costs from A to Stop or from } \\
\text { B to Stop }\end{array}$ & $300 \$$ \\
\hline $\begin{array}{l}\text { Switching costs from Stop to the tech- } \\
\text { nology used before the Stop (Ex.: A - }\end{array}$ & \\
Stop - A) & \\
\hline $\begin{array}{l}\text { Switching costs from Stop to the tech- } \\
\text { nology different as one used before the }\end{array}$ & $350 \$$ \\
Stop (Ex.: A - Stop - B) & \\
\hline
\end{tabular}

- The extracted oil is sold in the evening the same day at the current price of the world market. Warning: there is no link here between reality and the experiment.

- During the game, you receive information on market trends which you need to work out.

\section{Handling}


- At the beginning, in the first 2 introductory time periods, it will be shown the information possibilities and how to run the software.

- On the next page you will find a screenshot with the statements on the relevant parts.

\section{Examples of the performance calculation}

1. A player produces at the beginning of the game with technology A. After two periods he decides to stop the production. At the end of two periods, the price of oil is $56.4 \$$ and $62.8 \$$ respectively. The profit is calculated as follows:

$$
\begin{aligned}
& (56.4 \$ / \text { Barrel - } 61 \$ / \text { Barrel }) * 50 \text { Barrel - } 0 \$=-230 \$ \\
& (62.8 \$ / \text { Barrel - } 61 \$ / \text { Barrel }) * 50 \text { Barrel - } 0 \$=90 \$
\end{aligned}
$$

2. Then the player chooses to switch to technology B. With an oil price of $66.4 \$$ she earns at the 3-rd time period:

$$
(66.4 \$ / \text { Barrel - } 58 \$ / \text { Barrel }) * 25 \text { Barrel - } 300 \$=-90 \$
$$

\section{Initial wealth and pay-off calculation}

- You take on the oil field with the following settings: Wealth: 3000\$, current technology: B.

- The pay-off depends on the performance. The more dollars you have earned, the more money you get. Your profit will be calculated as follows:

Total profit $=\Sigma$ profits $P_{t}$ of all time periods;

Profit of a time period $\mathrm{Pt}=($ Oil price - Production costs $) *$ Number of produced barrels - Switching costs.

- You get a base salary of $10 \mathrm{CHF}$ for the participation in the experiment. For every extra dollar that you earn, you get 0,5 Rappen (i.e. $1 \$=0,005 \mathrm{CHF})$. In case of loss, you don't have to pay anything back.

- The paid amount is rounded by $2 \mathrm{CHF}$ 


\section{References}

Abbink, K. \& Rockenbach, B. (2006), 'Option pricing by students and professional traders: A behavioural investigation', Managerial and Decision Economics 27, 497-510.

Ackert, L. \& Church, B. K. (2001), 'The effects of subject pool and design experience on rationality in experimental asset markets', Journal of Psychology and Financial Markets 2(1), 6-28.

Ball, S. B. \& Cech, P.-A. (1996), 'Subject pool choice and treatment effects in economic laboratory research', Research in Experimental Economics 6, 239-292.

Banks, J., Camerer, C. \& Porter, D. (1994), 'An experimental analysis of nash refinements in signaling games', Games and Economic Behaviour 6, 1-31.

Brealey, R. A. \& Myers, S. C. (1991), Principles of Corporate Finance, 4th edn, McGraw-Hill Education.

Cadsby, C. B. \& Maynes, E. (1998), 'Laboratory experiments in corporate and investment finance: A survey', Managerial and Decision Economics 19, 277-298.

Dasgupta, P. \& Stiglitz, J. (1980), 'Uncertainty, industril structure and the speed of r\&d', Bell Journal of Economics, The RAND Corporation 11(1), 1-28.

Dean, J. (1951), Capital budgeting, Columbia University Press, New York.

Denrell, J. (2007), 'Adaptive learning and risk taking', Psychological Review 114(1), 177-187.

Dixit, A. \& Pindyck, R. S. (1994), Investment Under Uncertainty, Princeton University Press.

El-Gamal, M. A. \& Grether, D. M. (1995), 'Are people bayesian? uncovering behavioral strategies', Journal of the American Statistical Association 90(432), 1137-1145.

Erev, I., Ert, E., Roth, A. E., Haruvy, E., Herzog, S. M., Hau, R., Herwig, R., Steward, T., West, R. \& Lebier, C. (2010), 'A choice prediction competition: Choices from experience and from description', Journal of Behavioral Decision Making 23, 15-47. 
Ert, E. \& Erev, I. (2007), 'Replicated alternatives and the role of confusion, chasing, and regret in decisions from experience', Journal of Behavioral Decision Making 20, 305-322.

Gort, C., Wang, M. \& Siegrist, M. (2008), 'Are pension fund managers overconfident?', Journal of Behavioral Finance 9(3), 163-170.

Grenadier, S. R. (1995), 'Valuing lease contracts: A real-options approach', Journal of Financial Economics 38(3), 297-331.

Harvey, C. R. (1999), 'Identifying real options'. available online.

Hayes, R. H. \& Abernathy, W. J. (1980), 'Managing our way to economic decline', Harvard Business Review July-August, 67-77.

Hayes, R. H. \& Garvin, D. A. (1982), 'Managing as if tomorrow mattered', Harvard Business Review 60(3), 71-79.

Helson, H. (1964), Adaptation-level theory, Harper \& Row, New York.

Hollingworth, H. L. (1910), 'The central tendency of judgment', The Journal of Philosophy 7(17), 461-469.

Houser, D., Keane, M. \& McCab, K. (2004), 'Behavior in a dynamic decision problem: An analysis of experimental evidence using a bayesian type classification algorithm', Econometrica 72(3), 781-822.

Howell, S. D. \& Jägle, A. J. (1997), 'Laboratory evidence on how managers intuitively value real growth options', Journal of Business Finance and Accounting 24(7 \& 8), 915-935.

Kester, W. C. (1984), 'Todayś options for tomorrowś growth', Harvard Business Review 62, 153-160.

King, R. R., Smith, V. L., Williams, A. W. \& van Boening, M. (1992), The Robustness of Bubbles and Crashes in Experimental Stock Markets, Oxford Press, Oxford.

Kulatilaka, N. (1988), 'Valuing the flexibility of flexible manufacturing systems', IEEE Transactions in Engineering Management 35(4), 250-257.

Kulatilaka, N. (1992), 'Project valuation under uncertainty: When does def fail?', Journal of Applied Corporate Finance 5, 92-100. 
Lund, D. (1993), 'The lognormal diffusion is hardly an equilibrium price process for exhaustible resources.', Journal of Environmental Economics and Management 25, 235-241.

Marchiori, D. \& Warglien, M. (2008), 'Predicting human interactive learning by regret-driven neural networks', Science 319, 1111-1113.

Mason, S. P. \& Merton, R. C. (1985), The role of contingent claims analysis in corporate finance, in E. Altman \& M. Subrahmanyan, eds, 'Recent Advances in Corporate Finance', RIchard D. Irwin, Homwood, IL, pp. $7-$ 54 .

Miller, K. D. \& Shapira, Z. (2004), 'An empirical test of heuristics and biases affecting real option valuation', Strategic Management Journal 25, 269284.

Myers, S. (1977), 'Determinants of corporate borrowing', Journal of Financial Economics 5, 147-175.

OB́rien, J. \& Srivastava, S. (1993), Liquidity and persistence of arbitrage in experimental option markets, in D. Friedman \& J. Rust, eds, 'The Double Auction Market, Santa Fe Institute in the Science of Complexity', Vol. XIV, Addison Wesley, Reading, MA.

Odean, T. (1999), 'Do investors trade too much/', American Economic Review 89(1279-1298).

Paddock, J. L., Siegel, D. R. \& Smith, J. L. (1988), 'Option valuation of claims on real assets: The case of offshore petroleum leases', Quarterly Journal of Economics 103(3), 479-508.

Pindyck, R. S. \& Rubinfeld, D. L. (1991), Econometric Models and Economic Forecasts, McGraw-Hill Companies.

Rauchs, A. \& Willinger, M. (1996), 'Experimental evidence on the irreversibility effect', Theory and Decisions 40(1), 51-78.

Rockenbach, B. (2002), 'The behavioral relevance of mental accounting for the pricing of financial options', Journal of Economic Behavior and Organization 53, 513-527.

Schallheim, J. \& McConnell, J. J. (1983), 'Valuation of asset leasing contracts', Journal of Financial Markets and Portfolio Management 12(2), 237-261. 
Shavit, T., Sonsino, D. \& Benzion, U. (2002), 'On the evaluation of options on lotteries: An experimental study', Journal of Behavioral Finance 3(3), 168-181.

Siegel, S. \& Harnett, D. L. (1964), 'Bargaining behavior: A comparison between mature industrial personnel and college students', Operation Research 12, 334-343.

Smit, H. T. J. \& Trigeorgis, L. (2006), 'Real options and games: Competition, alliances and other applications of valuation and strategy', Review of Financial Economics 15, 95-112.

Titman, S. (1985), 'Urban land prices under uncertainty', American Economic Review 75(3), 505-514.

Trigeorgis, L. (1988), 'A conceptual options framework for capital budgeting', Advances in Futures and Options Research 3, 145-167.

Trigeorgis, L. \& Mason, S. P. (1987), 'Valuing managerial flexibility', Midland Corporate Finance Journal 5, 14-21.

Williams, J. (1991), 'Real estate development as an option', The Journal of

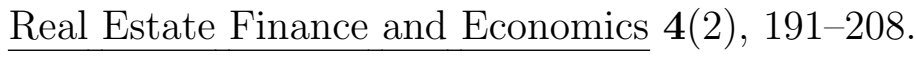

Yavas, A. \& Sirmans, C. F. (2005), 'Real options: Experimental evidence', The Journal of Real Estate Finance and Economics 31(1), 27-52. 